\title{
Research on Innovative Design of Lei Feng's Cultural and Tourism Souvenirs
}

\author{
Hong-he Gao ${ }^{1}$, Lu Han ${ }^{1}$ \\ ${ }^{1}$ School of Art\&design, Liaoning Shihua University, Fushun, Liaoning,113001, China
}

\begin{abstract}
Lei Feng's cultural tourist souvenirs are designed to meet the aesthetic needs of the young people. By purchasing red tourist souvenirs, consumers can enhance their understanding and communication of Lei Feng's spiritual culture, promote them social positive energy and promote regional tourism economic growth. According to the design principles and methods of red tourist souvenirs, the image features of Lei Feng and related red cultural features are accurately extracted, and combined with the current development status of red tourist souvenir market, the organic combination of Lei Feng and related red elements and tourist souvenirs is achieved. In view of the current lack of cultural design of Lei Feng tourist souvenirs. Through in-depth investigation and analysis of red elements related to lei Feng's tourist souvenirs that can deeply reflect the spirit and culture of Lei Feng.
\end{abstract}

\section{Introduction}

In May 2016, the State Council issued Opinions on Promoting the Development of Cultural and Creative Products in Cultural Relics Institutions (by the General Office of the State Council No. 36 (2016)), asking institutions of culture and cultural relics to develop cultural and creative products by relying on collection resources for in-depth mining and exploration..

However, the development of cultural and creative products is still in the initial stage of exploration, challenged by some unsolved issues, especially the development of red culture-based memorial products, which started late due to various restrictions. Such restrictions are mainly reflected in partial implementation of policies and incomplete management and incentive mechanism with insufficient consciousness and capability in innovation, design and product. In addition, the problems are worsened by the absence of diversity and social functions of products ${ }^{[1]}$, all of which have hampered the development of red culture-based creative products. Therefore, at present, domestic cultural relics need to actively promote the research and development of cultural and creative products, increase cultural consumption while extending and expanding the cultural communication functions of products, so as to improve economic and social benefits.

\section{Value of Lei Feng-related Cultural and Creative Product}

\subsection{New demands in the new age.}

*Corresponding author's e-mail: red_river@126.com
Since the 18th National Congress of the Communist Party of China (CPC), general secretary Xi Jinping has spoken on many occasions about Chinese traditional culture and cultural self-confidence, and red culture is an inseparable part of China's excellent traditional culture. The government encourages institutions of cultural relics to play an active role in the market by sorting out and sharing cultural resources, as emphasized by the Opinions on Promoting the Development of Cultural and Creative Products in Cultural Relics Institutions. The Outline of the 2016-2020 National Red Tourism Development Plan issued by the General Office of the CPC Central Committee and the General Office of the State Council clearly calls for promoting the development of red tourism through policy upgrading. Lei feng Memorial Hall, as a demonstration base for patriotic education, enjoys priority in the development of cultural and creative products.

\subsection{The functional requirements of the memorial hall.}

The functions of the memorial hall mainly include collection, education and scientific research, of which education plays the most important role among the three. As an ordinary worker in the time of peace, Lei Feng and his spirit keep encouraging generations of Chinese people. The Lei Feng Memorial Hall, located in Fushun, has been appointed as a National Patriotic Education Base, National Advanced Institution of the Building of Spiritual Civilization, and one of the first martyrs memorial building protection institution by the Publicity Department of CPC Central Committee and the Central Steering Committee of the Building of Spiritual Civilization[2]. Since the establishment of Lei Feng Memorial Hall in 1965, it has received up to 70 million 
visitors from home and abroad[3]. Development of Lei Feng-related cultural and creative products could help promote and spread the Lei Feng spirit, and set up an industrial chain of red culture-based creative products.

\subsection{The red culture-based creative products could serve as an efficient carrier of Lei Feng spirit.}

As a red culture-based creative product, the Lei Feng cultural and creative product is the result of prosperous red culture tourism, with growing need of people for products embodying red spirit. Unlike other souvenirs, Lei Feng cultural and creative products rely on the image of Lei Feng and his spirit, and are created by extracting the cultural elements in terms of style, pattern, craftsmanship and color to deliver aesthetic and practical values to the public[4]. The design of red culture- based products should function as spiritual motivation to distinguish itself from other cultural and creative products by fully displaying the Lei Feng spirit[5].The development of Lei Feng-based souvenirs is an efficient expansion and extension of existing exhibition, education and public services provide by the Lei Feng Memorial Hall, offering a chance to artistically recreate Lei Feng culture. Therefore, the development of Lei Feng-based cultural and creative products is of significance and necessity.

\section{Present Development of Lei Feng- based Cultural and Creative Products}

A national survey of Lei Feng-based cultural and creative products revealed that the efforts are still in an initial stage, with products focusing on character pendant, pins, bookmarks, water cup, bag, postcards, seal, model car, etc. Such products are usually of poor quality as shown in figure 1 .
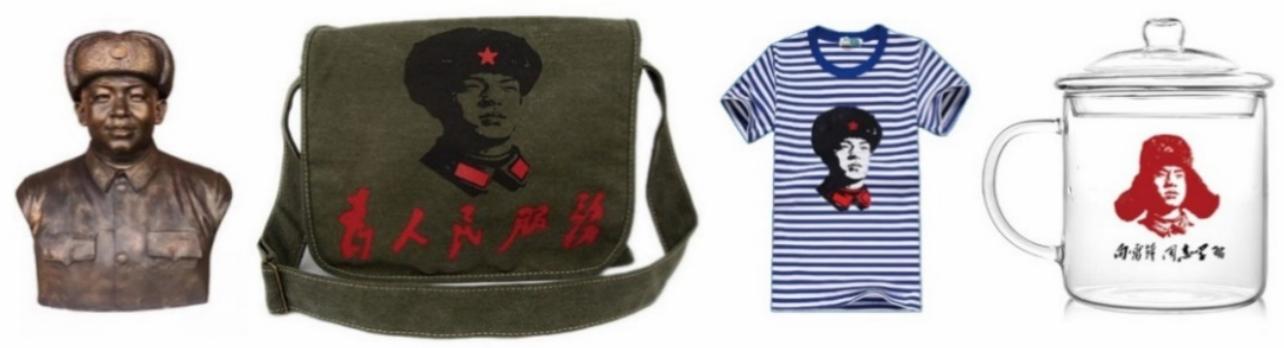

Figure 1: Current Lei Feng related tourist souvenirs.

Analysis of existing products found the following three common problems:

(1) Lack of innovation in design and absence of diversity. At present, changes are taking place in the consumption behavior of consumers, including preferences over original and customized products. On the other hand, products without distinction can hardly arouse desire from consumers, making it necessary to update products in time.

(2) The lack of cultural connotation in cultural and creative products. Most of the products, inconsistent with the corresponding cultural symbols, feature the lack of distinction and fail to carry on the Lei Feng spirit or meet the spiritual needs of consumers. Surveys have found that consumers pay more attention to the practical functions of tourist souvenirs, showing that products of poor quality would have little competency. In addition, most tourist souvenirs have a loose correlation with real life. In other words, they are not endowed with both practical and aesthetic values at the same time ${ }^{[6]}$. The evaluation criterion of products should be based on their functions, a factor valued by consumers.

(3) The products tend to be outdated. Taking existing Lei Feng-based cultural and creative products from Fushun as an example. Such products feature the lack of diversity and distinction without an overall design. Also, the old-fashioned package is in an urgent need of improvement to reveal the modern feature of red culture souvenirs based on the memorial hall.

\section{$4 \quad$ Analysis of the Design of Lei Feng-based Cultural and Creative Products}

The Lei Feng-based cultural and creative products are designed into models or other products. For model products, new processing technologies or manual work are applied to the existing pattern, guaranteeing perfect integration of craftsmanship and the Lei Feng spirit. Products with a distinct feature of the past age proves highly popular among consumers. As to the other products, the integration of cultural, memorial, aesthetic and practical values with attention to portability and environmental protection ensures the experience of consumers when using them.

\subsection{Analysis of design elements.}

4.1.1. Character. As a hero from the bottom of the class, Lei Feng is deeply loved by people. Therefore, the image of Lei Feng should be simple in design. In addition, more elements could be added to the image to enrich the character and meet people's aesthetic needs. For example, a cartoon image of Lei Feng would attract more children. For teenagers and adults, the image should be in a more abstract and realistic style.

4.1.2. Articles of daily use. Lei Feng lived a simple and prudent life, as evidenced by his "thrift box" and patched socks. With the increasing material abundance, there are 
more and more uncivilized phenomena such as extravagance and waste among the young people. Therefore, the government has advocated to save resources like food, clothes and water via programs such as "Clean Plate Campaign", "Clothes Donation Box", etc. It's clear that the Lei Feng spirit of hard work and simplicity is what today's young people lack, which should be carried on through improved design of such articles.

4.1.3. Life and work scenarios. The numerous stories of Lei Feng have deeply touched people, all of which have passed happiness and love to the future generations. The Lei Feng spirit could be integrated into the products, which would serve as a carrier to spread the Lei Feng spirit while bringing fun to the consumers.

4.1.4. Revolutionary weapon. As a solider of PLA, Lei Feng was often accompanied by steel guns and military vehicle. His love for vehicle is well known to the public. Also, vehicle and gun models are attractive to many male consumers. However, the gun models should meet the nation criteria for safety, especially the products for children.

4.1.5. Red culture symbol. As a classic symbol of red culture, red star is deeply rooted in the hearts of the people. The Lei Feng Memorial Hall in Fushun is decorated with red stars in many places. When visitors see red star, they will naturally associate it with the red culture. It is practical to explore symbols representing the red culture in the Lei Feng Memorial Hall of Fushun, like the Lei Feng's hat.

4.1.6. Icons of the memorial hall. The Lei Feng Memorial Hall of Fushun includes landscape such as the memorial hall, Monument of Lei Feng, and the statue of Lei Feng. A miniature of these iconic landscape that allows visitors to take it home could raise the public reputation of the memorial hall while bringing more economic benefits to the design of these products, forming a well-functioned industrial chain of the memorial hall.

\subsection{Design principles of Lei Feng-based cultural and creative products.}

As an ordinary but marvelous soldier, Lei Feng and his spirit will live in people's heart forever. It is an embodiment of the core values of Socialism and a heritage of the traditional Chinese culture. Therefore, the design of Lei Feng-based cultural and creative products should follow the rules below.

4.2.1. Avoid satirical or fun-poking design. With the development and progress of the society, people are having greater spiritual needs. In the meantime, there are people poking fun at classic revolutionary heroes. Such phenomenon would deviate the youth who know little about the past from the truth of history, and weaken the role of these heroes as a model for the young, thus preventing the young from learning from these heroes. The noble character of the hero and the positive energy brought by them deserve our respect, something no one is allowed to poke fun at.

\subsubsection{Integration of the red culture with local culture and} customs. Fushun, the hometown of Lei Feng, is also the origin of the Qing Dynasty and the Manchu nationality. It boasts landscape such as Qingyong Mausoleum and Hetula City. The unique history and folk customs of Fushuan endow the city with deep cultural foundation. The paper-cut art of the Manchu nationality reveals the mixture of bold and tender characters of northeastern people. In addition, the strong contrast of colors exerts profound aesthetic effect on consumers.

\subsubsection{Balance between industrial development of the} heritage of red culture. The spreading, development and protection of Lei Feng spirit should go together. Each scenic spot of red culture could serve as a classroom for the public. It is necessary to make a full use of the red resources for its spreading and passing to the next generation. The development of red tourism requires a thorough study of the important speeches by President Xi Jinping to enhance cultural self-esteem, patriotic education, protection and development of revolutionary, historic and cultural heritages, as well as expansion of tourism as new approach for economic development. Based on this, the design of cultural and creative products for the Lei Feng Memorial Hall in Fushun as a carrier of the Lei Feng spirit that allows consumers to "bring it home" is of practical significance, bringing consumers both fun and spiritual education.

4.2.4. Full utilization of local resources. Fushun is rich in natural resources with huge development potential. Amber, gagate and root carving produced by the West Open Pit of Fushun has been well known around the world. The integration of distinct local resources with the eternal Lei Feng spirit could promote the value of product as a collection and enhance its competency in the market. For example, When President Xi Jinping visited the Lei Feng Memorial Hall, he bought a Lei Feng ornament made of gagate from the West Open Pit.

\section{Practice of designing Lei Feng- based cultural souvenirs}

\subsection{Design method}

(1) Mind mapping. Mind mapping is the ultimate organizational thinking tool for note making in a creative and effective way by "drawing" ideas with words ${ }^{[8]}$.The ideas for the design of cultural and creative products for the Lei Feng Memorial Hall extend through perspectives such as landscape, the Lei Feng spirit, stationary tools, as well as articles used in life and revolution in the mind map, as shown in figure 2. Thus, a clear structure involving elements of cultural and creative products for the Lei Feng Memorial Hall is established, enriching the possibilities of innovation and creation. 


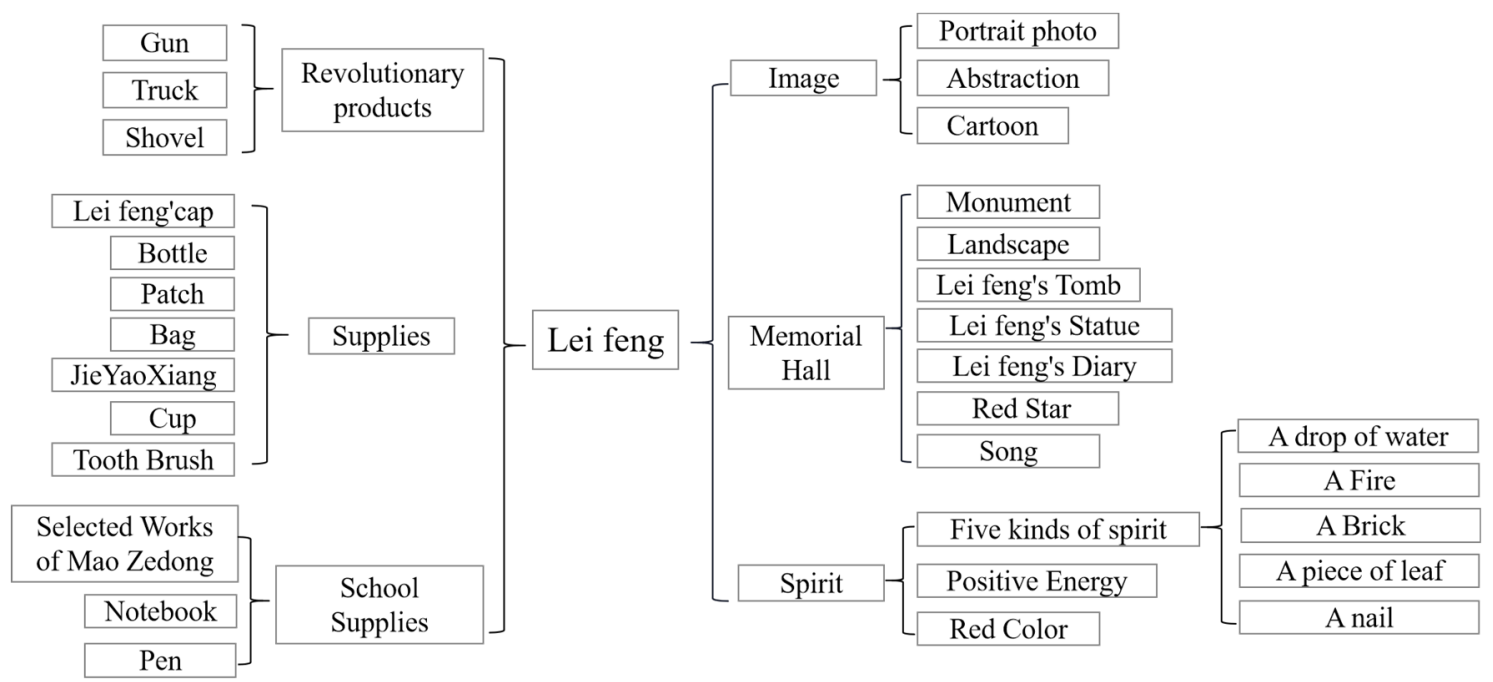

Figure2: Lei Feng cultural tourism souvenir mind map.

(2) Product matrix. Because the matrix diagram can add other design modes to the application column based on the square matrix sample apart from introducing other factors into the factor column, it could make a full use of each combination of the square matrix, thus filtering potential and possible ideas, and theoretically providing different concepts ${ }^{[9]}$. The Lei Feng-related design elements

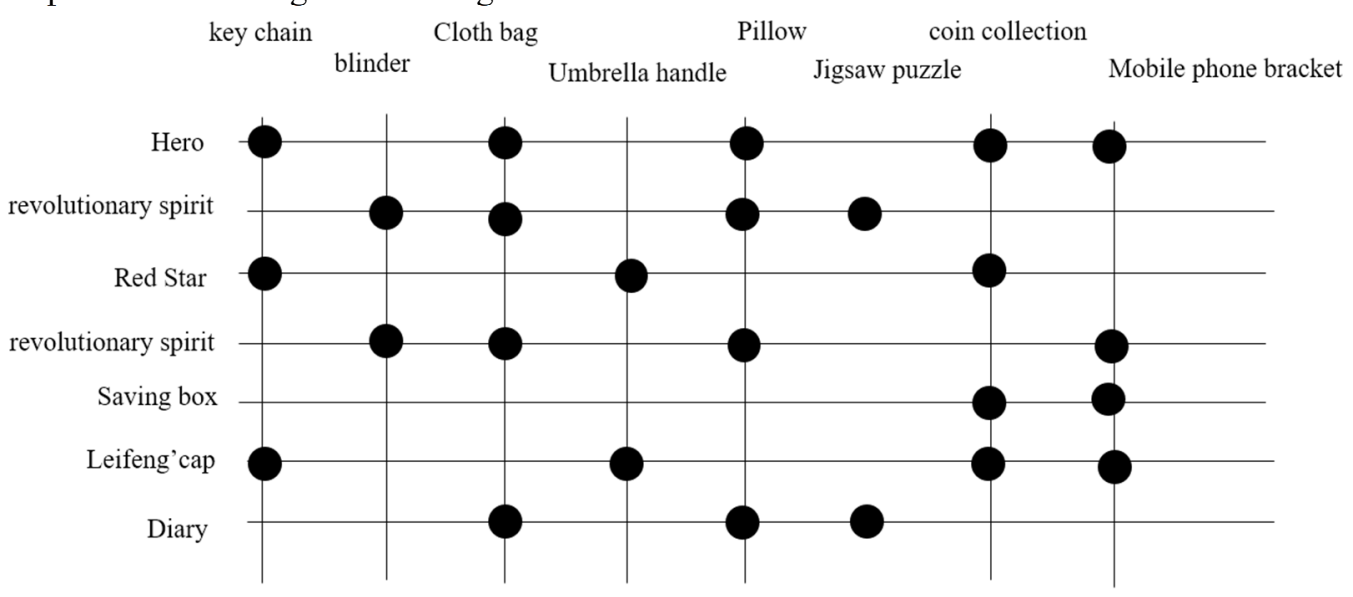

Figure 3: Lei Feng cultural tourist souvenir matrix.

\subsection{In-depth design}

A field survey of Lei Feng Memorial Hall showed that most Lei Feng-based red culture and creative products are weak in practical functions along with the lack of distinction and creativity, failing to meeting people's demands for aesthetic values. For these reasons, this kind of red tourist souvenirs are not favored by consumers. Feedback from consumers revealed a growing expectation of integrating customized and humane design with the red tourist souvenirs ${ }^{[10]}$. Therefore, the design will focus on daily products with practical functions.

Plan 1: Lei Feng cloth bag;

Inspiration: "I want to be a screw forever,"wrote Lei Feng in his diary. Side A of the cloth bag adopts thick are extracted through the mind map and refined in the matrix, as shown in figure 3 . Therefore, souvenirs with practical functions, such as key chain, phone holder, and cloth bag, along with products based on the image of Lei Feng, like patched socks, the thrift box and diaries, could be integrated into multiple design plans. 

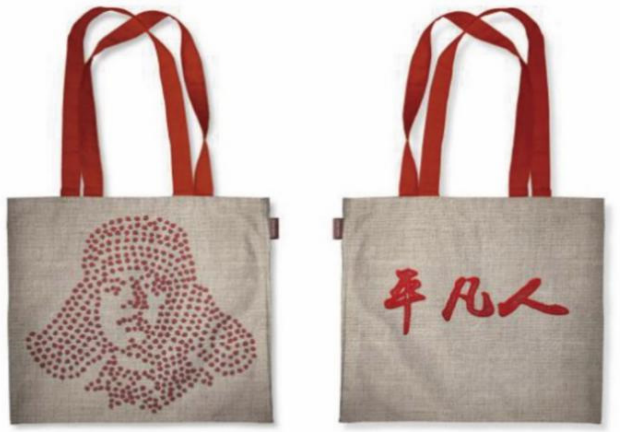

Figure4: The Lei Feng cloth bag.

The Lei Feng cloth bag describes the ordinary but marvelous life of Lei Feng using simple patterns and characters, and is well accepted by the public. The Lei Feng-based red cultural and creative products serve not only as a memorial of Lei Feng, but also a carrier to pass on his spirit. To make these products more competitive, the design adopts a "simple, distinct and abstract" style to make the carrier of Lei Feng's spirit more popular as a red tourist souvenir.

Plan 2: "Ordinary People" series patched household supplies;
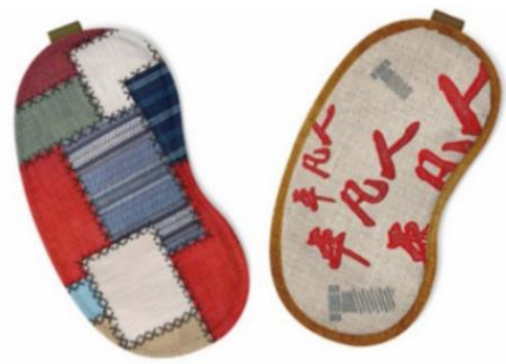

Inspiration: Lei Feng lived an extremely prudent life, as evidenced by his heavily-patched socks. The patch is a symbol of his thrift life, which is incorporated into the design. Patch has become a fashion among today's young people. Therefore, the design advocates for the virtue of thrifty of Lei Feng while meeting the aesthetic needs of young people.

The "Ordinary People" series patched household supplies use bold colors along with embroidery made of linen and coarse cloth. The patterns of the series offer both aesthetic and functional values, as shown in figure 5 .

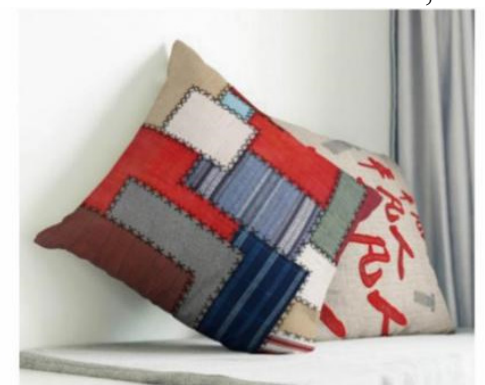

Figure5:"Ordinary People" Patch Series Household Supplies.

Plan 3: "Lei Feng's hat" multi-function product;

Lei Feng's hat has always been a classic element in Lei Feng-related products. By extracting the form of Lei Feng's hat into a cartoon image and endowing it with a variety of practical functions, it would be popular in the market. Lei Feng's spirit of helping others is what the current society advocates. "Lei Feng's hat", though simple in image, has a wide range of uses, making it a helpful tool for consumers, just as Lei Feng is giving a helping hand to them in their daily life. The delicate and small "Lei Feng's hat" can be taken along in the bag. It could be used as a mobile phone holder when in need. Consumers can also explore more functions, such as a pen holder, chopsticks holder, etc. It enhances user experience and helps them solve trivial problems in life. The design is shown in Figure 6.
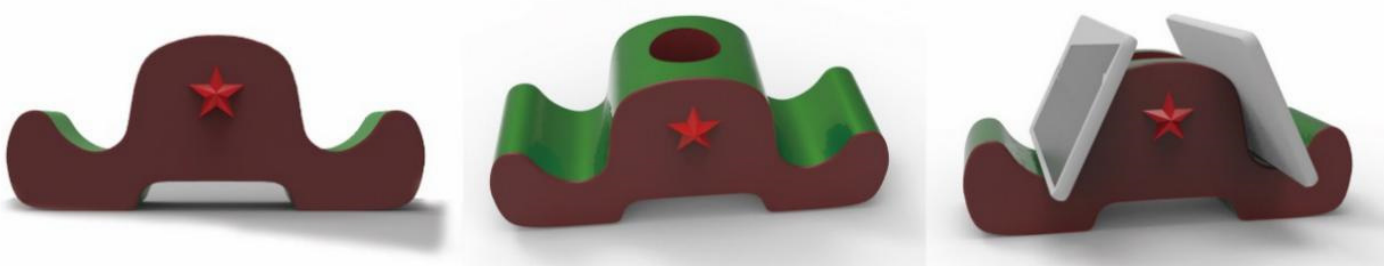

Figure6:"Lei Feng hat" multi-functional product.

\section{Analysis of the Design of Lei Feng- based Cultural and Creative Products}

The paper investigated the culture and characteristics of Lei Feng spirit through field study. It analyzed the collection resources to study the image of Lei Feng, his stories, culture, spirit, as well as the record of visits to the memorial hall. Based on the above efforts, the paper extracted elements in the design of cultural product for further development and research of these products. The paper proposes a set of cultural and creative products that advocate Lei Feng's spirit and socialist values while boasting marketing values, which could provide references for further development of Lei Feng-based cultural and creative products. 


\section{References}

1. Qing-mei J. (2016) Research and development of cultural and creative products in museum. Journal of $\mathrm{xi}$ 'an university of architecture and technology (social science edition), 35(6):42-46.

2. Shao-xiu Y. (2012) Introduction to Fushun Lei Feng memorial hall. Office business, 6:63-64.

3. Ming X. (2017) Building a distinctive urban cultural brand with the advantage of Lei Feng's cultural resources -- taking the Lei Feng memorial hall in Fushun as an example. China national exposition, $8: 222-224$

4. Shan-shan L. (2015) A brief analysis of the development and design of the museum's creative tourist souvenirs [J]. Art outlook, 12:132-133.

5. Long X, Fu-min Zh. (2015) Research on red tourism souvenir design. Packaging engineering, 20:151-155.
6. Ou L, Dian D, Bei-bei D. (2016) Exploration on the creative development of tourist souvenirs in Sanxingdui museum. China market, 17:181-182.

7. Zhong-yan Zh.( 2014) Design and creative ideas. Tongji university press, Shanghai.

8. Xiao-dong Y. (2008) Research on strategic planning of traffic development in Yan 'an based on red tourism. Chang 'an university, Xi'an.

9. Wen J, Shi-xiong Zh. (2004) A frame-based conceptual derivative instrument model. Modern manufacturing engineering, 2:102-104.

10. Mi-yun Q. (2016)The role of cultural creativity and products in the development of museums - a case study of capital museum . Journal of Shenyang Palace Museum, 2:45-48. 